\title{
Documentos
}

\section{La crisis económica y financiera de Asia.}

\author{
Discurso de su Excelencia Goh Chok Tong, \\ Primer Ministro de Singapur. ${ }^{1}$
}

\section{Introducción}

En este momento, la crisis económica y financiera del Asia tiene más de un año. Sin embargo, la perspectiva de una pronta recuperación parece cada vez más sombría. Las exportaciones han respondido de manera lenta, a pesar de la fuerte depreciación de las monedas regionales. Los índices bursátiles han continuado alcanzando bajas históricas. Los bancos se encuentran agobiados por el creciente número de préstamos incobrables y no pueden o no están dispuestos extender nuevos créditos, ni siquiera a firmas viables. El proceso de reestructuración de la deuda y la recapitalización de los bancos recién empiezan. Japón no está actuando con suficiente rapidez para enfrentar sus propios problemas bancarios ni para implementar un programa fiscal convincente que aumente su crecimiento. La presión sobre China para que devalúe su moneda continúa aumentando. A Hong Kong también se le presiona para que devalúe o para que rompa el vínculo con el dólar estadounidense. Y, aún peor, la crisis se ha extendido a mercados emergentes fuera del Asia. El rublo ha caído en

1 Discurso pronunciado en el Salon de Honor de la Universidad de Chile, el 1 de octubre de 1998, con motivo de su visita al Instituto de Estudios Internacionales. 
picada, mientras que los mercados financieros de muchos pases latinoamericanos dan muestras de confusión. En todo el mundo hay inversionistas nerviosos que buscan protegerse. La estabilidad del sistema financiero global no había estado tan precariamente equilibrada desde la Gran Depresión de la década del '30.

En mi discurso de hoy, compartiré con ustedes mi análisis de la crisis asiática. Además, haré una comparación entre la crisis asiática y la crisis de la deuda latinoamericana de los años '80.

\section{Factores subyacentes de la crisis asiatica}

La crisis asiática tuvo por telón de fondo un Asia Oriental en que varias economías operaban a toda marcha a comienzos de la década del '90. La región continúo mostrando un fuerte crecimiento, impulsado principalmente por grandes flujos de capital. Pero, la otra cara de este ingreso de capital y boom de la inversión era un alto déficit en cuenta corriente y una marcada inflación en los activos.

No hay nada de malo con un déficit en cuenta corriente ni con una entrada de capitales, siempre que los fondos se canalicen hacia inversiones que produzcan bienes y servicios que sean comerciables a nivel internacional. Pero los bancos asiáticos canalizaban la mayor parte de sus préstamos hacia el sector no comerciable, especialmente proyectos inmobiliarios grandiosos. La abundante oferta de fondos extranjeros baratos, elevó los precios de los activos, incrementó su valor prendario y permitió efectuar mayores préstamos, lo cual, a su vez, elevó los precios de los activos aún más. Era como un constante inyectar de aire caliente en un globo.

El hecho de que el tipo de cambio fuera fijo, hacía atractivas las bajas tasas de interés de los préstamos en monedas extranjeras. Una débil supervisión financiera facilitó prácticas bancarias temerarias: el uso de créditos a corto plazo para proyectos de largo plazo, los préstamos de fondos extranjeros para proyectos sujetos a ingresos nacionales y el exceso de inversiones. Más aún, gran parte del capital que entró se invirtió en valores en cartera de corto plazo, en lugar de destinarse a inversiones directas de largo plazo que desarrollaran la capacidad de producir bienes de exportación. 
Cuando en 1995 el dólar estadounidense comenzó a fortalecerse en relación al yen y a importantes monedas europeas, se suscitaron dificultades para las economías asiáticas. A causa de su vínculo con el dólar estadounidense, las monedas asiáticas también se revalorizaron en relación a las monedas de sus principales mercados de exportación. Esto, junto con el aumento de los costos, especialmente del mercado laboral, hizo que en 1996 se debilitara el crecimiento de las exportaciones, lo cual se agravó aún más por la caída de los precios de los productos básicos y por la importante declinación de la industria electrónica global.

Reducción de las exportaciones, aumento del déficit en cuenta corriente, incremento desenfrenado de los precios de los bienes raíces y de las acciones: éstas son condiciones que no se pueden sostener de manera indefinida. Cuando los comerciantes en monedas extranjeras y los especuladores vieron esto, vendieron en descubierto las acciones y las monedas de mayor vulnerabilidad. Cuando los acreedores y los inversionistas se dieron cuenta de que los márgenes de rentabilidad y rendimiento esperados no se producían, comenzó el pánico. Una vez comenzado, el pánico cundió. El globo se reventó. Los precios de los activos se derrumbaron, destruyendo los valores prendarios y aumentando los préstamos bancarios improductivos. El crédito bancario se contrajo, con lo cual los activos se desvalorizaron aún más, se creó un mayor número de préstamos incobrables y se destruyeron todavía más garantías prendarias. El flujo neto de capital se volvió negativo a medida que los fondos extranjeros buscaron salir apresuradamente.

Esta rápida salida creó presión en el tipo de cambio y en las reservas de divisas en el Asia. Inevitablemente, en un país tras otro, se abandonó el vínculo monetario. El 2 de julio de 1997 se dejó flotar el baht tailandés. Dentro de los dos meses siguientes, sucedió lo propio con el peso filipino, el ringgit malasio y la rupia indonesia. El 16 de diciembre también se dejó flotar el won coreano. Hasta ahora, estas monedas se han depreciado entre el 33\% y el $80 \%$ en relación al dólar estadounidense.

Para las compañías y los bancos que tenían préstamos sin protección en monedas extranjeras, el servicio de la deuda se disparó de tal forma que los llevó a la insolvencia. Para las compañías que tenían préstamos nacionales, el servicio también subió vertiginosamente debido al alza de las tasas de interés. El colapso de los precios de los activos hizo que 
aumentaran los préstamos improductivos, produciendo quiebras en cascada a través del sistema financiero y comprimiendo los sectores tanto inmobiliario como financiero.

\section{La crisis latinoamericana comparada con la crisis asiatica}

Al igual que la crisis asiática, la crisis de la deuda en América Latina estuvo precedida de un enorme flujo de capital hacia la región. En el caso de América Latina, el ingreso de capitales se realizó principalmente a través de préstamos oficiales destinados a financiar tanto profundos déficits fiscales como el creciente consumo privado. En Asia, la afluencia de capitales tomó la forma de carteras en los mercados de valores y préstamos al sector privado para financiar un auge inversionista. En ambos casos, la repentina pérdida de confianza por parte de los inversionistas y los importantes retiros de fondos extranjeros precipitaron la crisis. Qué llevó a esta repentina pérdida de confianza por parte de los inversionistas?

En el caso de América Latina, la reacción se produjo cuando los acreedores extranjeros se dieron cuenta de que las políticas macroeconómicas a que se aspiraba conducirían a desequilibrios externos insostenibles, lo cual daría lugar a probables incumplimientos en los pagos. En los países asiáticos, sin embargo, con anterioridad a la crisis se siguieron políticas macroeconómicas relativamente prudentes. Si bien algunas naciones latinoamericanas registraron una inflación alta y déficits fiscales profundos, en Asia la inflación era baja o moderada y los saldos presupuestarios, en general, mostraban equilibrio o excedentes. También a diferencia de América Latina, la tasa de ahorro en Asia era muy alta, y los déficits en cuenta corriente eran el resultado de un auge en las inversiones. En realidad, los relativamente sólidos fundamentos macroeconómicos de los países asiáticos fueron muy aclamados por analistas y organismos multilaterales como el FMI y el Banco Mundial. Esto puede haber contribuido a que los países asiáticos sintieran un exceso de confianza y seguridad en sí mismos con respecto a su vulnerabilidad externa.

Ciertos factores institucionales, especialmente los excesos en los sectores financiero y empresarial, desempeñaron un papel crucial en la crisis asiática, distinguiéndola de la crisis latinoamericana de comienzos 
de los años '80. A diferencia de América Latina, los países asiáticos enfrentan un problema de deuda tanto interna como externa. De hecho, el sobre endeudamiento interno y la crisis bancaria han pasado a ser los problemas centrales en Asia.

Una complicación adicional de la crisis asiática es la caída de los precios de los activos, especialmente de las acciones y de los inmuebles. La magnitud de la destrucción de riqueza es devastadora. En términos de las monedas locales, los índices de las bolsas de valores del Asia-en-crisis han bajado entre el $50 \%$ y el $60 \%$. En términos de dólares estadounidenses, los índices de los mercados bursátiles han caído entre el $70 \%$ y el $90 \%$. La riqueza destruida desde el 1 de julio de 1997 en las bolsas de Tailandia, Malasia, Indonesia y Corea solamente, alcanza a 480 mil millones de dólares, o 6,5 veces el PIB de Chile. Asimismo, en Indonesia, Malasia y Tailandia los inmuebles se han desvalorizado entre el $30 \%$ y el $50 \%$ con respecto a su nivel más alto.

A pesar de que los mercados bursátiles latinoamericanos también cayeron durante los años anteriores a la crisis de la deuda ${ }^{2}$, el impacto de esta caída sobre las economías respectivas fue menos grave, ya que las bolsas de valores latinoamericanas daban razón de una cantidad de riqueza proporcionalmente menor en comparación con los países asiáticos. En contraste, el patrimonio bursátil sobre el PIB antes de la crisis era de alrededor de $320 \%$ en Malasia y $90 \%$ en Tailandia. Han caído a alrededor de $70 \%$ y $30 \%$ respectivamente.

\section{¿Puede América Latina escapar de la gripe asiatica?}

América Latina no está inmune al virus asiático, dada la globalización de los mercados financieros actuales. La cuestión es cuán gravemente pueda verse afectada América Latina.

Es evidente que esta gravedad dependerá de los fundamentos económicos de cada uno de los distintos países. Afortunadamente, muchos

\footnotetext{
2 El îndice de los precios reales de la Bolsa de Buenos Aires subló de 82, a fines de 1977, a un nivel máximo de 377 a comienzos de 1980, para luego caer a un mínimo de 70 en 1982. Igualmente, la Bolsa chilena subió de 46 en 1977 a 381 en 1980 , antes de su caîda.
} 
países latinoamericanos no sufren de ciertas debilidades institucionales que afectan a los países asiáticos. En los últimos años, los sistemas financieros en Latinoamérica han sido objeto de reformas, y en la actualidad se encuentran sujetos a una supervisión más estrecha. Respecto de la deuda interna, el "leverage" no es tan alto, con un promedio que sólo llega a alrededor del $40 \%$, muy inferior al promedio de $120 \%$ existente en el Asiaen-crisis. Además, en comparación con las asiáticas, las compañías latinoamericanas no están tan expuestas a la deuda externa.

Para las economías latinoamericanas que tienen déficits fiscales y en cuenta corriente relativamente altos, el financiamiento de estos déficits constituirá un desafío importante en los próximos meses. El financiamiento externo se está volviendo cada vez más escaso y caro debido al aumento del costo de las primas de riesgo para los mercados emergentes. Es posible que sean necesarias ciertas restricciones en las políticas monetaria y fiscal para abordar los desequilibrios en las cuentas externas. Estas medidas implicarían cierto sufrimiento y llevarían a una marcada desaceleración de la economía, pero yo espero que el ajuste en América Latina no sea tan difícil, ya que en comparación con Asia, sus economías no tienen un "leverage" tan alto.

\section{Soluciones a la crisis económica}

Los pases asiáticos están respondiendo de maneras diferentes a sus dificultades económicas. Quisiera referirme a dos maneras importantes el control del capital y el método del FMI.

\section{Controles al capital. El método malasio}

El 1 de septiembre, Malasia impuso controles al capital, rompiendo radicalmente con las medidas ortodoxas prescritas por el FMI. El propósito de estos controles es proteger al ringgit malasio de los ataques especulativos, evitar la fuga de capitales y reducir las salidas de capitales de corto plazo. Para eliminar la volatilidad, Malasia ha fijado el tipo de cambio en RM 3,80 por US $\$ 1$, alrededor del $10 \%$ más alto que el imperante antes de los controles, pero $30 \%$ menos que el tipo de cambio previo a la crisis. Malasia 
no se encuentra bajo la supervisión del FMI, y por lo tanto puede optar por vía del control al capital.

Tras haber puesto en práctica los controles al capital, el gobierno malasio ha actuado con decisión para relajar la política monetaria a fin de aliviar el peso de la deuda empresarial y hacer arrancar la economía. Ha rebajado las tasas de interés interbancarias del 9,5\% al $8 \%$, y disminuido la reserva legal del $8 \%$ al $4 \%^{3}$. A los bancos se les ha dicho que deben aumentar sus préstamos en $8 \%$ este año y, de no hacerlo, deben dar explicaciones. El relajamiento monetario complementa el plan del gobierno malasio de emplear alrededor de1 $5 \%$ del PIB como parte de un programa de expansión fiscal.

Los controles al capital fueron impuestos luego de que se dieron a conocer datos que indicaban que la economía malasia había experimentado una fuerte contracción durante el segundo trimestre de este año. El gobierno responsabilizó por la desaceleración económica y la desvalorización de los activos primeramente a los especuladores en moneda y luego a las restrictivas políticas monetarias y fiscales prescritas por el FMI.

\section{El método del FMI}

Tailandia, Indonesia y Corea, a diferencia de Malasia, se encuentran bajo la supervisión del FMI porque necesitan de sus préstamos.

En general, la estrategia del FMI ha sido recomendar políticas destinadas a estabilizar el tipo de cambio y a restablecer la confianza de los inversionistas para que se produzca así un nuevo flujo de capitales hacia el país afectado. El FMI busca que mejoren las balanzas de pagos y que se establezcan reformas estructurales para reducir la inquietud de los inversionistas. Desgraciadamente, el entorno externo ha sido más adverso y los inversionistas más bajistas de lo que se esperaba. En consecuencia, las economías afectadas no han respondido de manera suficientemente rápida. No obstante, las tasas de interés internas, tanto en Tailandia como en Corea, han bajado notablemente en relación a sus niveles más altos y se

${ }^{3}$ El 1 de julio, el Banco Central rebajó la reserva legal en dos puntos porcentuales, del $10 \%$ al $8 \%$; el 1 de septiembre (el mismo día que se impusieron los controles al capital) la rebajó del $8 \%$ al $6 \%$, y el 7 de septiembre del $8 \%$ al $4 \%$. 
ha empezado a producir una importante afluencia de capitales a estos países. En Indonesia, sin embargo, las recomendaciones del FMI aún no han dado resultados, en parte a causa de la situación política. Como consecuencia de su experiencia, el FMI últimamente se ha vuelto más flexible y más dispuesto a considerar políticas monetarias y fiscales menos restrictivas para apoyar la actividad económica y suavizar el impacto social de la crisis.

Es demasiado pronto para juzgar el éxito que puedan tener las drásticas medidas tomadas por Malasia. En gran parte, esto dependerá de que el gobierno malasio use el respiro proporcionado por los controles impuestos al capital a fin de defenderlo de los ataques especulativos, para recapitalizar y reactivar los bancos, así como para reformar los sectores empresarial y bancario. Es una movida audaz, con altos riesgos. Existe el peligro de que un relajamiento excesivo de las políticas monetaria y fiscal empeore la balanza comercial, incentive la fuga de capitales, disminuya las reservas de divisas y debilite la confianza.

\section{Impacto de la crisis en Singapur y nuestra respuesta}

¿Qué sucede en Singapur? Si bien los fundamentos económicos de Singapur son relativamente sólidos, la nación no está aislada de la crisis regional. La enorme disminución de la demanda externa proveniente de la región ha causado una baja en nuestras exportaciones de bienes y servicios, con efectos negativos que han alcanzado otros sectores de la economía. Estos factores externos, en gran parte, se encuentran fuera del control de Singapur y no constituyen problemas inherentes a la economía nacional. La velocidad de nuestro crecimiento se ha moderado notablemente, por lo cual se prevé que el aumento del PIB este año sea mínimo, a diferencia de 1.997, cuando nuestra expansión fue del 7,8\%

En respuesta a estas dificultades, el gobierno de Singapur ha adoptado diversas medidas. Por ejemplo, para enfrentar la volatilidad del tipo de cambio, nuestra autoridad monetaria (MAS) está manejando el tipo de cambio del dólar de Singapur con mayor flexibilidad. El objetivo es mantener la estabilidad de los precios y la confianza tanto en el dólar como en el sistema financiero de Singapur sin perder la competitividad. 
Singapur está reduciendo los costos de la actividad comercial a fin de ayudar a sus empresas a enfrentar este difícil período. Se disminuirá el valor de los arriendos de tierras industriales pertenecientes al gobierno y se rebajarán impuestos, tasas y comisiones. Se ha impuesto una profunda moderación de los salarios, y hasta es posible que disminuyan. Además, el gobierno de Singapur ha aumentado el gasto en inversiones en la infraestructura económica para mejorar la capacidad productiva de la economía. Entre estos proyectos se cuentan la extensión del puerto, la construcción de escuelas, la expansión del sistema de transporte público, la inversión en informática y el readiestramiento de los trabajadores.

\section{Conclusión: Lecciones aprendidas}

Para concluir, quisiera extraer ciertas lecciones de la crisis asiática.

Primero, las autoridades nacionales deben permanecer vigilantes en todo momento y mantener una constante disciplina macroeconómica, especialmente en las épocas de auge, cuando es fácil bajar la guardia. Aquí, he observado que Chile ha impuesto medidas para desalentar la entrada de capitales a corto plazo ${ }^{4}$. Todavía existe un gran debate sobre los beneficios y los costos de restringir la afluencia de capital, pero lo que es más importante es el hecho de que las autoridades hayan decidido no sucumbir al atractivo del dinero barato para proyectos especulativos e improductivos.

Segundo, es esencial establecer un sistema financiero sólido y robusto, que sea capaz de soportar las sacudidas externas. En vista de los estrechos lazos que actualmente existen entre las economías mundiales, es imposible aislarse de los remezones externos. Por lo tanto, se debe estar preparado para hacer frente a las ocasionales tormentas y pánicos financieros que es probable que se produzcan.

Tercero, los países deben mejorar la infraestructura regulatoria y legislativa sobre la cual se sustenta una economía de mercado, como la buena dirección corporativa y el código de quiebras. Una mayor

4 En Chile, para la compra de títulos o valores de renta fija por parte de los no residentes, se exige una reserva de $30 \%$ por 1 año, y la tenencia por un plazo minimo de 1 año. Ademâs, las ganancias de capital están sujetas a la reglamentación tributaria que rige los impuestos a la renta en general. 
transparencia reducirá la ineficiencia económica y una legislación clara permitirá resoluciones más rápidas en caso de producirse quiebras comerciales.

Finalmente, quisiera subrayar la naturaleza global de la actual crisis económica y financiera del Asia y hacer un llamado a los países industrializados -especialmente a Estados Unidos, Japón y Europa- para que consideren emprender acciones coordinadas en el terreno de las políticas monetarias, fiscales y comerciales. Las acciones conjuntas destinadas a reducir las tasas de interés a nivel global pueden aliviar gran parte de la presión sobre las monedas asiáticas, incrementar la demanda total global y estabilizar los profundos vaivenes en los valores en cartera en los mercados emergentes. Las expansiones fiscales coordinadas pueden ayudar a estimular las exportaciones de las economías que están en recuperación. Espero que la última propuesta hecha por el Presidente Bill Clinton con respecto a acciones concertadas por parte del G-7 resulte en una mayor urgencia y determinación para enfrentar la crisis.

Es de suma importancia mantener políticas comerciales abiertas y resistir las presiones proteccionistas si los mercados emergentes han de aliviar el peso de su deuda externa a través de las exportaciones y estabilizar su tipo de cambio. Al colaborar con los países en desarrollo y los organismos multilaterales para mejorar el funcionamiento de los mercados financieros globales, los países industrializados pueden desempeñar un papel clave en cuanto a minimizar la probabilidad de que se repita esta crisis financiera global y, si se repitiera, en cuanto a detener sus contagiosos efectos. 